\title{
Association of socioeconomic status and receipt of colorectal cancer investigations: a population- based retrospective cohort study
}

\author{
Sheldon M. Singh, Lawrence F. Paszat, Cindy Li, Jingsong He, Chris Vinden, Linda Rabeneck
}

\section{Abstract}

Background: Although the Canadian health care system was designed to ensure equal access, inequities persist. It is not known if inequities exist for receipt of investigations used to screen for colorectal cancer (CRC). We examined the association between socioeconomic status and receipt of colorectal investigation in Ontario.

Methods: People aged 50 to 70 years living in Ontario on Jan. 1, 1997, who did not have a history of CRC, inflammatory bowel disease or colorectal investigation within the previous 5 years were followed until death or Dec. 31, 2001. Receipt of any colorectal investigation between 1997 and 2001 inclusive was determined by means of linked administrative databases. Income was imputed as the mean household income of the person's census enumeration area. Multivariate analysis was performed to evaluate the relationship between the receipt of any colorectal investigation and income.

Results: Of the study cohort of 1664188 people, 21.2\% received a colorectal investigation in 1997-2001. Multivariate analysis demonstrated a significant association between receipt of any colorectal investigation and income $(p<0.001)$; people in the highest-income quintile had higher odds of receiving any colorectal investigation (adjusted odds ratio [OR] 1.38; 95\% confidence interval $[\mathrm{Cl}]$ 1.36-1.40) and of receiving colonoscopy (adjusted OR 1.50; 95\% Cl 1.48-1.53).

Interpretation: Socioeconomic status is associated with receipt of colorectal investigations in Ontario. Only one-fifth of people in the screening-eligible age group received any colorectal investigation. Further work is needed to determine the reason for this low rate and to explore whether it affects CRC mortality

CMAJ 2004;171(5):461-5<smiles>[O]</smiles>
olorectal cancer (CRC) is the most common cause of cancer-related death among nonsmokers in Canadians will receive a diagnosis of CRC and 8400 will die from the disease. ${ }^{1}$ Although the age-standardized incidence and mortality of CRC have been decreasing, the number of new cases is increasing because of the growing size of the elderly population.

CRC screening reduces the incidence and diseasespecific mortality, ${ }^{2-6}$ is cost-effective ${ }^{7,8}$ and is endorsed by many professional societies. ${ }^{9-15}$ In 1994 the Canadian Task Force on the Periodic Health Examination (now the Canadian Task Force on Preventive Health Care) concluded that there was insufficient evidence to support CRC screening in asymptomatic people over the age of 40 years. ${ }^{16}$ In the 2001 update of these guidelines ${ }^{9}$ fecal occult blood testing (FOBT) every 1 or 2 years or flexible sigmoidoscopy every 5 years was recommended for screening average-risk people 50 years of age or older; there was judged to be insufficient evidence to support colonoscopy as the initial screening test. Despite these endorsements the use of CRC screening remains suboptimal. ${ }^{17-19}$

The Canadian health care system covers all medically necessary services without user fees. Although equity has been achieved in certain areas, ${ }^{20,21}$ low socioeconomic status (SES) is associated with a lower rate of use of cardiovascular procedure ${ }^{22,23}$ and screening tests for breast and cervical cancer. ${ }^{24-26} \mathrm{It}$ is unknown whether SES affects the receipt of CRC screening investigations. This study assessed the association of neighbourhood income (a marker of SES) with the receipt of colorectal investigations in people eligible for screening who lived in Ontario.

\section{Methods}

Data were obtained from the Ontario Registered Persons Database (RPDB), the Ontario Health Insurance Plan (OHIP) database and the Canadian Institute for Health Information (CIHI) database. The RPDB contains demographic information on all Ontario residents ever covered under OHIP. The OHIP database records all physician claims in Ontario. The CIHI database contains diagnostic and procedural information on all patients discharged from hospitals and same-day surgery units. These databases have high rates of reliability for demographic, diagnostic and procedural information. ${ }^{27}$

Inclusion and exclusion criteria for the study cohort are summarized in Box 1. People aged 50 to 70 years living in Ontario on Jan. 1, 1997, who had a valid OHIP number were identified in the RPDB. Those who in the previous 5 years had had CRC, inflammatory bowel disease or colorectal investigation were excluded. The remainder approximated a cohort at average risk of CRC. People with missing geographic or suppressed income data were excluded. 
A longitudinal record was created, and each person was followed until death or Dec. 31, 2001. People were classified as living in urban or rural areas according to 1996 Statistics Canada Census definitions ${ }^{28}$ applied to the postal code of the primary address. Health status on Jan. 1, 1997, was assessed with the Deyo score, as follows. Weights were assigned for specific comorbid conditions (e.g., myocardial infarction, diabetes mellitus without complications, renal disease), and a score was calculated for each person in the cohort with the use of codes of the International Classification of Diseases, 9th revision, recorded in the hospital discharge abstracts between Jan. 1, 1992, and Dec. 31, 1996, according to the method described by Deyo, Cherkin and Ciol. ${ }^{29}$ With this approach, a score of 0 indicates no comorbidity, and higher scores denote higher levels of comorbidity.

People who received any colorectal investigation (FOBT, barium-enema radiography, sigmoidoscopy, colonoscopy) were identified in both the OHIP and CIHI databases; Appendix 1 lists the procedural and diagnostic codes. Using administrative

\section{Box 1: Inclusion and exclusion criteria for the study cohort}

\section{Inclusion criteria}

Age 50 to 70 years inclusive on Jan. 1, 1997

Valid Ontario Health Insurance Plan number

Living in Ontario, Canada, on Jan. 1, 1997

Registered in the Ontario Registered Persons Database

\section{Exclusion criteria}

Colorectal cancer diagnosed between Jan. 1, 1992, and Dec. 31, 1996

Inflammatory bowel disease between Jan. 1, 1992, and Dec. 31, 1996

Colorectal investigation between Jan. 1, 1992, and Dec. 31, 1996

Missing or invalid address or suppressed income data data, one cannot distinguish between screening and diagnostic investigations; however, identifying these procedures in an average-risk population approximates identifying screening procedures.

Because personal income is not included in Ontario administrative databases, we used 1996 Statistics Canada Census data to calculate the mean household income of the enumeration area in which the person lived. An enumeration area is the geographic area canvassed by 1 census representative; in 1996 the number of dwellings in each enumeration area varied from 125 to 440 . The enumeration areas were classified into quintiles, each containing approximately $20 \%$ of the Ontario population, that were based on the mean household income: $\$ 34370$ for the first quintile, $\$ 47792$ for the second, \$56244 for the third, \$65 949 for the fourth and $\$ 95066$ for the fifth. Census data have previously been used as a surrogate for personal income. ${ }^{21-23,26,30,31}$

We used analysis of variance (for continuous variables) and $\chi^{2}$ tests (for categorical variables) to determine if any statistically significant difference existed across income quintiles and between the group that received colorectal investigations and the group that did not. We used multivariate logistic regression to evaluate the independent association of income and receipt of any investigation, adjusting for age, sex, location of primary address (rural or urban) and the Deyo score; we calculated 95\% confidence intervals (CIs) for each value. We performed separate analyses for people who received colonoscopy and those who did not. The level of statistical significance was set at $p<0.05$.

We obtained approval for the study from the Sunnybrook and Women's College Health Sciences Centre Research Ethics Board.

\section{Results}

Of the 1810702 people in the inception cohort, 3.2\% had missing geographic data, and $4.9 \%$ had suppressed income data. The remaining 1664188 (91.9\%) constituted the study cohort.

The mean age of the study cohort was 58.6 years, $49.9 \%$ were male, $14.3 \%$ lived in rural areas, and $91 \%$ had a Deyo

Table 1: Baseline characteristics of the study cohort $(n=1664$ 188)

\begin{tabular}{|c|c|c|c|c|c|c|}
\hline \multirow[b]{2}{*}{ Variable } & \multicolumn{5}{|c|}{ Income quintile } & \multirow[b]{2}{*}{$p$ value* } \\
\hline & 1 & 2 & 3 & 4 & 5 & \\
\hline Mean income, Can\$ & 34370 & 47792 & 56244 & 65949 & 95066 & \\
\hline No. (and \%) of people & 314988 (18.9) & $335054(20.1)$ & 338799 (20.4) & 328922 (19.8) & 346425 (20.8) & \\
\hline Age, mean (and SD), yr & $59.0(6.1)$ & $59.1(6.1)$ & $58.8(6.1)$ & $58.4(6.0)$ & $58.0(6.0)$ & $<0.001$ \\
\hline Male, \% & 48.6 & 49.2 & 49.9 & 50.8 & 51.1 & $<0.001$ \\
\hline Rural residence, \% & 15.4 & 22.9 & 18.7 & 11.4 & 3.5 & $<0.001$ \\
\hline Deyo score,$\uparrow \%$ & & & & & & $<0.001$ \\
\hline 0 & 89.1 & 89.8 & 90.6 & 91.5 & 92.9 & \\
\hline 1 & 5.9 & 5.5 & 5.1 & 4.6 & 3.7 & \\
\hline 2 & 3.0 & 2.9 & 2.7 & 2.5 & 2.3 & \\
\hline$\geq 3$ & 2.0 & 1.8 & 1.6 & 1.4 & 1.1 & \\
\hline
\end{tabular}

Note: $\mathrm{SD}=$ standard deviation.

*In analysis of variance for continuous variables and $\chi^{2}$ tests for categorical variables.

†Determined by summing weights for comorbid conditions, as coded in hospital discharge abstracts between Jan. 1, 1992, and Dec. 31, 1996, for each person in the cohort, according to the method described by Deyo et al. ${ }^{29}$ 
score of 0 . There were no imbalances in age, sex or Deyo score between the groups with and without complete data. During follow-up, 151854 died.

Table 1 summarizes the baseline characteristics of the study cohort. For all demographic characteristics there were small differences among the income quintiles: people in higher-income quintiles tended to be younger, be male, live in urban areas and have a lower Deyo score.

Table 2 compares the $21.2 \%$ of the study cohort who received any colorectal investigation during the follow-up period with those who did not. There were small but significant differences between the 2 groups: those who received any colorectal investigation tended to be older, be female, live in urban areas and have a higher Deyo score. Of those who received any colorectal investigation, a greater proportion had higher incomes.

Table 3 displays the results of the multivariate analysis for receipt of any colorectal investigation in the follow-up period. Higher age, female sex, urban residence and a moderate Deyo score (1 or 2) were independent predictors of receiving colorectal investigations. After adjustment for all variables, people in higher-income quintiles had increased odds of receiving any colorectal investigation. Those in the highest-income quintile had 1.38 higher odds of receiving any investigation than those in the lowest.

Table 4 displays the results of the multivariate analysis for receipt of colonoscopy in the follow-up period. Higher age, female sex and rural residence were independent predictors of receiving colonoscopy. After adjustment for these variables, people in higher-income quintiles had increased odds of receiving colonoscopy. Those in the highestincome quintile had 1.50 higher odds of receiving colonoscopy than those in the lowest.

\section{Interpretation}

We observed a marked association between income and receipt of colorectal investigations in a screening-eligible age group in Ontario. Increased income was associated with 1.38 higher odds of receiving any colorectal investigation and 1.50 higher odds of receiving colonoscopy. In addition, during a 5-year period about one-fifth of people in the screening-eligible age group in Ontario received any colorectal investigation. As we could not distinguish screening from diagnostic investigations, this value represents the upper extent of CRC screening.

Despite universal health care, Canadians of higher SES still have greater access to certain medical procedures than Canadians of lower SES;2-26 our findings add to the earlier work. In addition, the rate of screening for CRC in Ontario is low; in the United States in 2001, by comparison, about $20 \%$ of the population received FOBT, and $43 \%$ had undergone lower endoscopy in the previous 10 years. ${ }^{18}$ Screening rates may be suboptimal owing to factors affecting decision-making by physicians ${ }^{19,32-35}$ and patients. ${ }^{36-40}$ Universal health insurance alone may not reduce SES differences in health care; ${ }^{41}$ organized screening programs may be necessary to reduce the disparity. ${ }^{26}$

It is important to acknowledge the limitations of our methodology. First, our results do not pertain strictly to screening, because administrative databases do not distinguish screening from diagnostic investigations. To approximate an average-risk cohort, we studied people in the screening-eligible age group who had no history of previous CRC, inflammatory bowel disease or colorectal investigations. Although not perfect, our analysis reasonably estimated the receipt of screening investigations. For certain, the proportion screened was less than $21 \%$. Second, al-

Table 2: Comparison of those who received any colorectal investigation* between

Jan. 1, 1997, and Dec. 31, 2001, and those who did not

\begin{tabular}{lccl}
\hline Variable & Any investigation & No investigation & $p$ value* $^{*}$ \\
\hline No. (and \%) of people & $352930(21.2)$ & $1311258(78.8)$ & \\
Age, mean (and SD), yr & $59.2(6.1)$ & $58.5(6.1)$ & $<0.001$ \\
Male, \% & 48.6 & 50.3 & $<0.001$ \\
Rural residence, \% & 13.8 & 14.4 & $<0.001$ \\
Deyo score, \% & & & $<0.001$ \\
0 & 89.7 & 91.1 & \\
1 & 5.7 & 4.7 & \\
2 & 3.1 & 2.6 & \\
$\geq 3$ & 1.5 & 1.6 & \\
Income quintile, \% & & & \\
1 & 16.7 & 19.5 & \\
2 & 19.3 & 20.4 & \\
3 & 20.4 & 20.4 & \\
4 & 20.4 & 19.6 & \\
5 & 23.3 & 20.2 & \\
\hline
\end{tabular}

*Fecal occult blood testing, barium-enema radiography, sigmoidoscopy, colonoscopy. 
though census data have been used as a surrogate for personal income in the past, total wealth may be a more appropriate marker of financial resources in the elderly. Finally, our main outcome was receipt of colorectal investi-

\section{Table 3: Results of multivariate logistic regression analysis for receipt of any colorectal investigation in the follow-up period} $(n=1664188)$

\begin{tabular}{lll}
\hline Variable & $\begin{array}{c}\text { Unadjusted OR } \\
\text { (and 95\% Cl) }\end{array}$ & $\begin{array}{c}\text { Adjusted OR } \\
\text { (and 95\% Cl) }\end{array}$ \\
\hline $\begin{array}{l}\text { Age } \\
\text { Sex }\end{array}$ & $1.02(1.02-1.02)$ & $1.02(1.02-1.02)$ \\
$\quad \begin{array}{l}\text { Female } \\
\quad \text { Male }\end{array}$ & 1.00 & 1.00 \\
Primary residence & $0.93(0.93-0.94)$ & $0.93(0.92-0.94)$ \\
$\quad$ Urban & 1.00 & 1.00 \\
$\quad$ Rural & $0.95(0.94-0.96)$ & $0.98(0.97-1.00)$ \\
Deyo score & & \\
0 & 1.00 & 1.00 \\
1 & $1.22(1.20-1.24)$ & $1.20(1.18-1.22)$ \\
2 & $1.21(1.18-1.23)$ & $1.16(1.14-1.19)$ \\
$\geq 3$ & $1.01(0.98-1.04)$ & $0.97(0.94-1.00)$ \\
Income quintile & & \\
1 & 1.00 & 1.00 \\
2 & $1.11(1.10-1.12)$ & $1.10(1.10-1.12)$ \\
3 & $1.17(1.15-1.18)$ & $1.18(1.16-1.19)$ \\
4 & $1.22(1.20-1.23)$ & $1.24(1.22-1.25)$ \\
5 & $1.35(1.33-1.36)$ & $1.38(1.36-1.40)$ \\
\hline
\end{tabular}

Note: $\mathrm{OR}=$ odds ratio, $\mathrm{Cl}=$ confidence interval.

Table 4: Results of multivariate logistic regression analysis for receipt of colonoscopy in the follow-up period $(n=1664$ 188)

\begin{tabular}{lll}
\hline Variable & $\begin{array}{c}\text { Unadjusted OR } \\
\text { (and 95\% Cl) }\end{array}$ & \multicolumn{1}{c}{$\begin{array}{c}\text { Adjusted OR } \\
\text { (and 95\% Cl) }\end{array}$} \\
\hline $\begin{array}{l}\text { Age } \\
\text { Sex }\end{array}$ & $1.018(1.018-1.019)$ & $1.017(1.016-1.018)$ \\
$\quad \begin{array}{l}\text { Female } \\
\text { Male }\end{array}$ & 1.00 & 1.00 \\
Primary residence & $0.95(0.94-0.96)$ & $0.94(0.93-0.95)$ \\
$\quad$ Urban & 1.00 & 1.00 \\
$\quad$ Rural & $1.16(1.14-1.18)$ & $1.22(1.20-1.24)$ \\
Deyo score & & \\
0 & 1.00 & 1.00 \\
1 & $1.40(1.36-1.43)$ & $1.37(1.34-1.41)$ \\
2 & $1.38(1.34-1.42)$ & $1.33(1.29-1.37)$ \\
$\geq 3$ & $1.31(1.26-1.37)$ & $1.27(1.22-1.33)$ \\
Income quintile & & \\
1 & 1.00 & 1.00 \\
2 & $1.14(1.12-1.16)$ & $1.12(1.10-1.14)$ \\
3 & $1.17(1.14-1.19)$ & $1.17(1.15-1.19)$ \\
4 & $1.21(1.18-1.23)$ & $1.24(1.22-1.26)$ \\
5 & $1.42(1.40-1.45)$ & $1.50(1.48-1.53)$ \\
\hline
\end{tabular}

gations, not quality of life, survival or death. Previous work has demonstrated a small improvement in survival rates for patients of higher SES with CRC in Ontario. ${ }^{42}$ It will be important to determine whether a decreased risk of death from CRC was conferred on the people who received colorectal investigations in our cohort.

In conclusion, inequities in receipt of colorectal investigations exist in Ontario. In addition, fewer than 21\% of people in the screening-eligible age group were screened for CRC between 1997 and 2001. Further work is necessary to determine why this disparity exists, explore its effects on CRC mortality and move forward with an organized screening program to improve CRC screening.

This article has been peer reviewed.

From the Department of Medicine (Singh, Rabeneck) and the departments of Radiation Oncology and Health Policy, Management and Evaluation (Paszat), University of Toronto, Toronto, Ont., the Institute for Clinical Evaluative Sciences, Toronto, Ont. (Paszat, Li, He, Vinden, Rabeneck), and the Department of Surgery, University of Western Ontario, London, Ont. (Vinden)

Competing interests: None declared.

Contributors: Sheldon Singh, Lawrence Paszat and Linda Rabeneck conceived and designed the study. Cindy $\mathrm{Li}$, Jingsong He and Chris Vinden acquired the data. Sheldon Singh, Lawrence Paszat, Cindy Li, Jingsong He and Linda Rabeneck analyzed and interpreted the data. All authors either drafted the manuscript or revised it critically, and all approved the version to be published.

Acknowledgements: We thank Ms. Deanna Rothwell for her assistance with statistical analysis and commentary on the final manuscript. Dr. Rabeneck is a Senior Investigator with the Cancer Quality Council of Ontario.

\section{References}

1. National Cancer Institute of Canada. Canadian cancer statistics 2004. Toronto: The Institute; 2004. p. 24, 26.

2. Winawer SJ, Zauber AG, Ho MN, O'Brien MJ, Gottleib LS, Sternberg SS, et al. Prevention of colorectal cancer by colonoscopic polypectomy. $N$ Engl 7 Med 1993;329:1977-81.

3. Mandel JS, Bond JH, Church TR, Snover DC, Bradley GM, Schuman LM, et al. Reducing mortality for colorectal cancer by screening for fecal occult blood. N Engl 7 Med 1993;328:1365-71.

4. Hardcastle JD, Chamberlain JO, Robinson MH, Moss SM, Amar SS, Balfour TW, et al. Randomized controlled trial of fecal-occult-blood screening for colorectal cancer. Lancet 1996;348:1472-7.

5. Kronborg O, Fenger C, Olson J, Jorgensen OD, Sondergaard O. Randomized study of screening for colorectal cancer with fecal-occult blood test. Lancet 1996;348:1467-71.

6. Selby JV, Friedman GD, Quesenberry CP, Weiss NS. A case-controlled study of sigmoidoscopy and mortality from colorectal cancer. $N$ Engl $7 \mathrm{Med}$ 1992;326:653-7.

7. Pignone M, Saha S, Hoerger T, Mandelblatt J. Cost-effectiveness analysis of colorectal cancer screening: a systematic review for the U.S. Preventive Services Task Force. Ann Intern Med 2002;137:96-104.

8. Frazier AL, Colditz GA, Fuchs CS, Kuntz KM. Cost-effectiveness of screening for colorectal cancer in the general population. FAMA 2000;284:1954-61.

9. Canadian Task Force on Preventive Health Care. Colorectal cancer screening. Recommendation statement from the Canadian Task Force on Preventive Health Care. CMA7 2001;165(2):206-8.

10. United States Preventive Services Task Force. Clinical guidelines: screening for colorectal cancer: recommendations and rationale. Ann Intern Med 2002; 137:129-31.

11. Rex DK, Johnson DA, Lieberman DA, Burt RW, Sonnenberg A. Colorectal cancer prevention 2000: screening recommendations of the American College of Gastroenterology. Am 7 Gastroenterol 2000;95:868-77.

12. Smith RA, von Eschenbach AC, Wender R, Levin B, Byers T, Rothenberger $\mathrm{D}$, et al. American Cancer Society guidelines for the early detection of cancer: update of early detection guidelines for prostate, colorectal, and endometria cancers. Also: update 2001 - testing for early lung cancer detection. CA Cancer 7 Clin 2001;51:38-75.

13. Winawer S, Fletcher R, Rex D, Bond J, Burt R, Ferrucci J, et al. Colorectal 
cancer screening and surveillance: clinical guidelines and rationale - update based on new evidence. Gastroenterology 2003;124:544-60.

14. Winawer SJ, Fletcher RH, Miller L, Godlee F, Stolar MH, Mulrow CD, et al. Colorectal cancer screening and surveillance: clinical guidelines and rationale. Gastroenterology 1997;112:594-642.

15. Feldman GE, McCord CW, Frieden TR. Preventing colorectal cancer. City Health Inf 2003;22(2):1-4.

16. Solomon MJ, McLeod RS. Screening for colorectal cancer. In: Canadian Task Force on the Periodic Health Examination. Canadian guide to clinical preventive health care. Ottawa: Health Canada; 1994. p. 798-809.

17. Hiatt RA, Klabunde C, Breen N, Swan J, Ballard-Barbash R. Cancer screening practices from national health interview surveys: past, present and future. 7 Natl Cancer Inst 2002;94:1837-46.

18. Colorectal cancer test use among people $\geq 50$ years, United States, 2001. MMWR Morb Mortal Wkly Rep 2003;52:193-6.

19. Rabeneck L, Paszat L. A population based estimate of the extent of colorectal cancer screening in Ontario. Am 7 Gastroenterol 2004;99:1141-4.

20. Finkelstein MM. Do factors other than need determine utilization of physicians' services in Ontario? CMA7 2001;165(5):565-70.

21. Shortt SED, Shaw RA. Equity in Canadian health care: Does socioeconomic status affect waiting times for elective surgery? CMA7 2003;168(4):413-6.

22. Anderson GM, Grumbach K, Luft HS, Roos LL, Mustard C, Brook R. Use of coronary artery bypass surgery in the United States and Canada: influence of age and income. $7 A M A$ 1993;269:1661-6.

23. Alter DA, Naylor CD, Austin P, Tu JV. Effects of socioeconomic status on access to invasive cardiac procedures and on mortality after acute myocardial infarction. N Engl 7 Med 1999;341:1359-67.

24. Katz SJ, Hofer TP. Socioeconomic disparities in preventive care persist despite universal coverage. Breast and cervical screening in Ontario and the United States. 7AMA 1994;272:530-4.

25. Katz SJ, Zemencuk JK, Hofer TP. Breast cancer screening in the United States and Canada: socioeconomic gradients persist. Am 7 Public Health 2000; 90:799-803.

26. Gupta S, Roos LL, Walid R, Traverse D, Dahl M. Delivering equitable care: comparing preventive services in Manitoba. Am f Public Health 2003;93:2086-92.

27. Goel V, Williams JI, Anderson GM, Blackstein-Hirsch P, Fooks C, Naylor CD, editors. Patterns of health care in Ontario. The ICES practice atlas. $2 \mathrm{nd}$ ed. Ottawa: Canadian Medical Association; 1996. p. 339-45.

28. Statistics Canada. Postal code conversion file: detailed user guide. Ottawa: Geography Division, Statistics Canada; 1988.

29. Deyo RA, Cherkin DC, Ciol MA. Adapting a clinical co-morbidity index for use with ICD-9-CM administrative databases. 7 Clin Epidemiol 1992;45:613-9.

30. Wilkins R. Use of postal codes and addresses in the analysis of health data. Health Rep 1993;5:157-77.

31. Kreiger N. Overcoming the absence of socio-economic data in medical records: validation and application of a census-based methodology. Am $7 \mathrm{Pub}$ lic Health 1992;82:703-10.

32. Schattner A, Gilad A. Primary care physicians' awareness and implementation of screening guidelines for colorectal cancer. Prev Med 2002;35:447-52.

33. Woolf SH. Overcoming the barriers to change: screening for colorectal cancer. Am Fam Physician 2001;61:1621.

34. Ling BS, Moskowitz MA, Wachs D, Pearson B, Schroy PC. Attitudes towards colorectal cancer screening tests: a survey of patients and physicians. 7 Gen Intern Med 2001;16:822-30.

35. Ellerbeck EF, Engelman KK, Gladden J, Mosier MC, Raju GS, Ahluwalia JS. Direct observation of counseling on colorectal cancer in rural primary care practices. 7 Gen Intern Med 2001;16:697-700.

36. Davis TC, Dolan NC, Ferreira MR, Tomori C, Green KW, Sipler AM, et al. The role of inadequate health literacy skills in colorectal cancer screening. Cancer Invest 2001;19:193-200.

37. Weinrich SP, Weinrich MC, Boyd MD, Johnson E, Frank-Stromborg M. Knowledge of colorectal cancer among older persons. Cancer Nurs 1992;15: 322-30.
38. Powe B. Fatalism among elderly African Americans: effects on colorectal cancer screening. Cancer Nurs 1995;18:385-92.

39. O'Malley AS, Forrest CB, Mandelblat J. Adherence of low-income women to cancer screening recommendations: the roles of primary care, health insurance and HMOs. 7 Gen Intern Med 2002;17:144-54.

40. McIssac WJ, Fuller-Thomson E, Talbot Y. Does having regular care by a family physician improve preventive care? Can Fam Physician 2001;47:70-6.

41. Adler NE, Boyce WT, Chesney MA, Folkman S, Syme L. Socioeconomic inequalities in health. No easy solution. FAMA 1993;269:3140-5.

42. Boyd C, Zhang-Salomons JY, Groome PA, Mackillop WJ. Associations between community income and cancer survival in Ontario, Canada and the United States. 7 Clin Oncol 1999;17:2244-55

Correspondence to: Dr. Linda Rabeneck, Sunnybrook and Women's College Health Sciences Centre, 2075 Bayview Ave., Rm. D406, Toronto, ON M4N 3M5; fax 416 480-5804; linda.rabeneck@sw.ca

\begin{tabular}{lc}
\hline Appendix 1: Procedural and diagnostic codes \\
\hline Classification & Code \\
\hline
\end{tabular}

\section{OHIP procedural codes}

Fecal occult blood testing

L181, G004

Barium-enema radiography

Single-contrast

$\mathrm{X} 112$

Double-contrast

$\mathrm{X} 113$

Sigmoidoscopy

Rigid

Z535

Rigid + biopsy

Z536

Flexible; 60-cm scope $\quad$ Z580

Flexible to splenic flexure $\quad$ Z580 + E740

Colonoscopy

To hepatic flexure

To cecum

To terminal ileum

\section{CIHI CPP procedural codes}

Sigmoidoscopy

Colonoscopy

$Z 555+E 740+E 741$

$\mathrm{Z} 555+\mathrm{E} 740+\mathrm{E} 741+\mathrm{E} 747$

$\mathrm{Z} 555+\mathrm{E} 740+\mathrm{E} 741+\mathrm{E} 747+\mathrm{E} 705$

\section{CIHI ICD-9 diagnostic codes}

Colorectal cancer

01.24

$01.2,01.22$

Inflammatory bowel disease

Ulcerative colitis

153.0 to $153.4,153.6$ to 154.1

Crohn's disease

$556,556.0$ to 556.9

$555,555.0$ to 555.9

Note: $\mathrm{OHIP}=$ Ontario Health Insurance Plan, $\mathrm{ClHI}=$ Canadian Institute for Health Information, $\mathrm{CPP}=$ Canadian Classification of Diagnostic, Therapeutic, and Surgical Procedures, ICD-9 = International Classification of Diseases, 9th revision. 